\title{
ANTICIPACIONES DEL ERASMISMO ESPAÑOL EN EL LUMEN AD REVELATIONEM GENTIUM DE ALONSO DE OROPESA
}

\footnotetext{
A la memoria de Marcel Bataillon y Américo Castro, maestros admirados por la riqueza y la escrupulosa integridad de sus enseñanzas y entrañablemente queridos por su bondad humana.
}

Bien conocidos son los problemas surgidos en la España del siglo $\mathrm{XV}$ respecto a los cristianos de origen judío, cuyo papel en la vida social y religiosa se intentó circunscribir, si no eliminar, con "estatutos de limpieza de sangre". También conocemos algunos de los tratados lanzados en el mismo siglo XV contra los promotores de los estatutos discriminatorios. Pero, aunque se han estudiado estos tratados 'con referencia al problema converso, no se ha examinado con suficiente atención otro aspecto interesante que presentan: su enlace con el erasmismo que iba a tener tanta importancia en España durante las primeras décadas del siglo XVI.

Marcel Bataillon fue uno de los primeros en proponer la posibilidad de encontrar notas pre-erasmistas en los escritos que los conversos dirigieron contra sus perseguidores. En el prólogo a la primera edición de la traducción española de su Erasmo y Espa$\tilde{n} a$ (México, 1950), sugirió que los orígenes de los movimientos espirituales del siglo XVI en España debieran buscarse "en los grandes conversos del siglo XV y en los origenes de la tan hispánica orden de los jerónimos" lo cual haría "más inteligible el enlace de lo hispánico con el erasmismo" (p. xiii). Aún más se acercó al problema que nos interesa ahora confesando que, al señalar el tema del cuerpo místico como típico del paulinismo erasmista, lo hizo "con la duda de si habría otra fuente próxima desatendida por mí" (p. xv). Aunque Bataillon declaró que por aquel entonces - el prólogo fue escrito en julio de 1949 - todavía nadie había señalado tal fuente, nos dejó, sin embargo, con una conje- 
tura muy acertada. Pues, notando que conversos como Juan de Ávila y Alejo Venegas fueron entre los espirituales españoles del siglo XVI los que mayor resonancia dieron a la metáfora paulina, se preguntó Bataillon "si, en España, el paulinismo tuvo exactamente el sentido universalista que defendía el Apóstol de los Gentiles frente a la Sinagoga, y si el enaltecer el cuerpo místico tuvo aquí algo de reacción contra el prejuicio de la limpieza de sangre en que «se encastillaban», como dice Venegas, los cristianos viejos ufanos de su linaje, limitadores inconscientes (en su antijudaísmo) del viejo racismo judío" (pp. xv-xvi) ${ }^{1}$.

Un examen del Lumen ad revelationem gentium et gloria plebis Dei Israel, recientemente publicado en traducción castellana aunque todavía inédito en el latín original ${ }^{2}$, del General de la Orden de San Jerónimo, Alonso de Oropesa, confirma

${ }^{1}$ Sobre el exclusivismo de los hebreos, véase ahora el estudio de BENZion Netanyahu, "Américo Castro and his views on the origins of the Pureza de Sangre", The American Academy for Jewis Research, Proceedings, ts. 46-47, 1979-80, pp. 397-457. Netanyahu rechaza rotundamente la idea de Castro de que la preocupación de los cristianos viejos en España con la limpieza de sangre fuera una adaptación cristiana de un exclusivismo racial de largo abolengo entre los judíos. Sin entrometernos ahora en esta discusión, lo que sí importa señalar es que la idea de tal exclusivismo entre los judíos era un lugar común esgrimido por lo menos desde el siglo XV en España, tanto por cristianos nuevos como por los cristianos viejos. Éstos, con citas del Antiguo Testamento, intentaban justificar los estatutos de limpieza de sangre, viendo a los conversos bien pagados con ellos por el alegado exclusivismo de sus antepasados. Los cristianos nuevos, por su parte, condenaban los estatutos discriminatorios contra los de sangre judía precisamente en nombre de la superación de la ley del Antiguo Testamento por la ley de gracia de Jesucristo y aun había quienes denunciaban como "judaizante" el exclusivismo racial de los cris. tianos viejos.

${ }^{2}$ ALONSO DE OROPESA, Luz para conocimiento de los gentiles, estudio, traducción y edición de Luis A. Díaz y Díaz, Madrid, 1979. La obra fue comenzada en 1450 cuando estallaron revueltas entre cristianos viejos y nuevos en el monasterio jerónimo de Nuestra Señora de Guadalupe, poco después de entrar allí fray Alonso. La terminó en 1465, ya General de la Orden de San Jerónimo, a insistencia del Arzobispo de Toledo, Alfonso de Carrillo, siendo la ocasión los intentos de ciertos frailes franciscanos de renovar sentimientos anticonversos con calumnias y falsos rumores contra los cristianos de sangre judía. Respecto a la edición de Díaz y Díaz, es una lástima que no la haya hecho bilingüe, tratándose de una obra de gran importancia que se cita con tanta frecuencia según el resumen de Sigüenza en su Historia de la Orden de San Jerónimo (en la edición de la NBAE, t. 1, capítulo XIX), sin conocimiento alguno del texto original en latín. En el presente trabajo me referiré a dos manuscritos de que tengo copias, el ms. 27 de la Biblioteca Provincial de Guadalajara (G) y el ms. A 3 INF de la Biblioteca Ambrosiana de Milán (A). También citaré los lugares correspondientes de la traducción de Luis Díaz y 
sobradamente la razón que tenía Bataillon. En esta obra, el autor jerónimo (y casi seguramente converso) ${ }^{3}$, en efecto, no sólo recurrió a la figura paulina en el sentido sugerido por el perspicaz hispanista francés, sino que también tocó una cantidad de cuestiones de que más tarde habían de ocuparse los aficionados a Erasmo en España.

Comenzando con lo que quizás sea más evidente, el celo mis mo con que Oropesa compulsó textos bíblicos, escritos de los santos padres de la Iglesia y aun alguno que otro texto de la antigüedad clásica, procurando sacar su sentido original que le sirviera para autorizar sus propias ideas sobre la cuestión conversa, ya podría considerarse una anticipación de procedimientos que más tarde emplearían los erasmistas. Desde luego, no queremos sugerir que Oropesa ya fuera un biblista y humanista equiparable a los del siglo XVI. Pero lo que sí cabe afirmar es que el primer paso en esa dirección, los primeros individuos que encontraron un estímulo apremiante para escudriñar los textos mencionados, lo dieron Oropesa y sus contemporáneos, por sus preocupaciones con el problema de los conversos, sin duda alguna el problema religioso y social más candente del siglo XV en España.

De una manera indirecta, fray José de Sigüenza, el historiador de la Orden de San Jerónimo, parece confirmar lo que acabamos de proponer. Escribiendo hacia principios del siglo XVII, este fraile jerónimo (a quien Bataillon incluyó en su capítulo sobre "últimos reflejos de Erasmo" en España) francamente expresó su asombro de encontrar en escritores como Oropesa remotos precursores de los que desplegaron, como dice Sigüenza, "un buen gusto de letras" en España, tanto que "no dudaré ponerle con los muy buenos deste tiempo"4. Es significativo que, aunque Sigüenza

Díaz (DíAz). No he visto un tercer manuscrito, el ms. 1753 de la Biblioteca Universitaria de Salamanca que, según Díaz y Díaz, "no es una edición cuidadosa" (p. 56 de su Introducción).

${ }^{3}$ Díaz y Díaz lo declara "hijo de cristianos viejos" (p. 7) sin reconocer la existencia de lo que escribió Francisco Márquez Villanueva para indicar la gran probabilidad, si no la seguridad absoluta, del linaje converso de Oropesa (véase F. MÁRQUEZ, Investigación sobre Juan Álvarez Gato, Madrid, 1960, pp. 132, 141 y también su "Estudio preliminar" a la edición de la Católica impugnación por fray Hernando de Talavera que hizo Francisco Martín Hernández, Barcelona, 1961, pp. 9, 15). En el capítulo IV del Lumen, Oropesa mismo se permite declarar que "después de Noé" cuando "se dividieron las razas" no hubo nadie en su linaje de quien se pudiera sospechar ser del género judío, aserción hiperbólica que hace dudar, a mi ver, la verdad de lo que pretende negar (G., fol. 1lr; A., fol. 31r; DíAZ, p. 101).

${ }^{4}$ Op. cit., t. $1,369 \mathrm{a}$. 
añadió que "desta manera entiendo que auia otros muchos en otras religiones de España, cuyas obras estaran sepultadas en essas librerias...", el único a quien nombró fue Pablo de Santa María, el Obispo de Burgos que antes de bautizarse en 1390 fue Salomón Ha-Leví, rabino mayor de Burgos. Impresionó a Sigüenza el "libro tan docto" de don Pablo, el Scrutinium scripturarum en que el ex rabino empleó sus conocimientos del hebreo y de los talmudistas para "deshazer los errores de sus hermanos los ludios" y traerles "al conocimiento de nuestra santa fe" 5 . Lo notable para nosotros es que ambos "pre-humanistas" destacados por el historiador jerónimo aplicaron sus conocimientos y talentos al perenne problema judío de España, aunque en etapas dramáticamente opuestas de su desarrollo. Pues apenas veinte años separaron la llamada de Santa María a los judíos a la pila bautismal del giro histórico que obligó a Oropesa a defender a los judíos recientemente bautizados de las persecuciones que les infligieron sus nuevos correligionarios cristianos ${ }^{6}$.

Sigüenza hubiera podido destacar también a don Alonso de Cartagena, hijo de Santa María y sucesor suyo en el obispado de Burgos, quien, como autor del Defensorium unitatis christianae, fue otro notable por el "buen gusto de letras" en el siglo XV. Para nosotros, el Defensorium, escrito en 1449 para defender a los conversos de sus perseguidores de Toledo, tiene un interés especial, porque, ocupándose de la misma cuestión que Oropesa trata en el Lumen, permite reconocer la mayor aproximación de éste al espíritu erasmista.

La obra de Cartagena es, al pie de la letra, un "defensorium" de la unidad cristiana, en que el autor, procediendo como un fiscal, reúne textos bíblicos, eclesiásticos y clásicos para armar su pleito contra los que sembraron divisiones entre los fieles con el establecimiento del bien conocido Sentencia-Estatuto de 1449, el

${ }^{5}$ Ibid. Según Sigüenza, Santa María escribió el Scrutinium en 1437, pero Luciano Serrano observó que don Pablo mismo declaró que lo acabó en 1432; véase Serrano, Los conversos $D$. Pablo de Santa María y D. Alfonso de Cartagena, Madrid, 1942, p. 112.

${ }^{6}$ Irónicamente, el Lumen que Oropesa compuso en 1450 para defender a los conversos se hizo necesario, en gran parte, gracias a los escritos de conversos como Pablo de Santa María, Jerónimo de Santa Fe (Hebraeomastix) y Micer Pedro de la Caballería (Zelus Christi contra iudaeos et sarracenos). La virulencia de su caracterización del "judío pérfido" no podía menos de hacer dudar a las masas cristiano-viejas de la eficacia del bautismo para redimirle. Las discriminaciones de limpieza de sangre que Oropesa denunció en el Lumen fueron fomentadas inicialmente por la plebe para quien la figura del "judío traidor" quedaba siempre presente en la persona del bautizado judeocristiano. 
primer estatuto de limpieza de sangre en España ${ }^{7}$. En toda la armazón apretada de su argumentación, no se le escapa a Cartagena ninguna nota de una nueva sensibilidad religiosa suya como eclesiástico. En efecto, a pesar de tratarse de una cuestión religiosa - la de la unidad de todos los fieles en la fe de Jesucristo-, Cartagena parece haber concebido su obra como un instrumento más bien político, puesto que acabó dirigiéndola al Rey don Juan II a quien tocó, según el obispo, proceder contra los inculpados malhechores ${ }^{8}$.

Al lado de Cartagena, se nota en seguida el temple particular de Oropesa, reflejo quizás de su formación en el seno de la devoción contemplativa de la Orden de San Jerónimo. Confrontado con el problema de la discriminación anticonversa, el jerónimo, en vez de responder con una sencilla argumentación, emprende un examen radical y complejo de la fe cristiana en que los cristianos viejos pretendieron encastillarse contra los de origen judaico. Y por este camino acaba expresando ideas sobre la religión cristiana cuya importancia alcanza mucho más allá de su preocupación inicial. Oropesa mismo se mostró consciente del alcance de su obra al terminarla, notando que podía parecer excesivamente voluminosa para su propósito original, pero que en realidad tenía que considerarse demasiado breve. Pues, por la importancia del asunto, había tenido que entrar en "la selva de la ley" donde resultó difícil separar las materias que se le presentaron entrelazadas como las ramas de los árboles selváticos ${ }^{9}$.

Para ejemplificar la inclinación de Oropesa a seguir el hilo de su preocupación principal con la discriminación anticonversa a la consideración amplia de cualquier problema intermedio que se le presentara, podemos detenernos con él en la cuestión de la interpretación de los textos bíblicos. Este problema surgió para él, así como para Cartagena en el Defensorium, mientras procuraba no sólo autorizar sus propias opiniones, sino también im-

\footnotetext{
${ }^{7}$ Eugenio Asensio pretende enseñarme que el estatuto de Toledo no fue el primero y se obstina en su idea de que ya en 1414 el Colegio Viejo de San Bartolomé tenía un estatuto que excluía a los que no eran ex puro sanguine (véase su artículo "En torno a Américo Castro. Polémica con Albert A. Sicroff", $H R, 40$, 1972, p. 384). Antonio Domínguez Ortiz, de acuerdo conmigo, escribe: "En los estatutos de 1414 [de San Bartolomé] se dice que los miembros del colegio debían ser ex puro sanguine, pero estimo con Sicroff, que esta expresión no alude a la limpieza de sangre en el sentido que después se le dice" (véase su libro* Los judeoconversos en España y América, Madrid, 1971, p. 80, nota 2).

${ }^{8}$ Alonso de Cartagena, Defensorium unitatis christianae, ed. P. Manuel Alonso S. I., Madrid, 1943, capítulos XIII, XIV y "ultilogus", pp. 309-320.

${ }^{9}$ G., fols: 191v-192r; A., 454r; Díaz, p. 763 .
} 
pugnar las de sus contrarios que, según él, abusaban de la Sagrada Escritura para fines particulares. Cartagena despachó bastante rápidamente este asunto, reconociendo que se podrían sacar múltiples sentidos de la Biblia, afirmando sencillamente, sin embargo, la primacía del sentido litera $l^{10}$. Oropesa, por su parte, no perdió la ocasión de expresarse ampliamente sobre cómo había que leer los textos sagrados, ofreciendo ideas que más tarde se pudieran tomar por las de Erasmo. Podrían ser del holandés mismo las amonestaciones de Oropesa contra los peligros de tomar al pie de la letra las palabras de la Biblia mientras se descuidaba el significado que tenían dentro de su contexto. De semejante literaíismo, observó Oropesa, se puede incurrir en lo más absurdo. Ejemplo de ello sería el espectáculo de frailes que se han visto pasear cargando en los hombros cruces de madera que ellos mismos fabricaron, creyendo quc de esta manera cumplían con las palabras "quien no toma su cruz y me sigue no es digno de mí", que se leen en Mateo, $\mathrm{X}, 38^{\prime \prime}$.

10 "Nam licet multi sensus in sacra scriptura sumantur veri et utiles et ad salutem nostram proficui. litteralis tamen prior, solidior et memorabilior est. ex illo namque quasi ex quadam radice ceteri progediuntur" (Defensorium, ed. cit., pp. 98-99. Sigo la ortografía y la puntuación de la edición).

11 “...certum es quod evangelium non est in verbis tantum, sed in semenciis, sicut scribitur prima q. prima Marchion: Nec putemus inquit in verbis Scripturarum esse evangelium sed in sensu, non in superficie sed in medula, non in sermonum foliis sed in radice racionis... De quo ut unum solum brevitatis causa adducam exemplum, quidam districtissimi monachorum habentem quidem zelum Dei, sed non secundum scienciam attendentes id quod ex Christi precepto scriptum est in evangelio, scilicet, qui non accipit crucem sua met sequitur me non est me dignus, illudque male intelligentes fecerunt sibi cruces ligneas, easque iugiter humeris circumferentes, non edificationem sed risum cunctis videntibus intulerunt..." ( $G$, fol. 135r; A, fols. 324r-v; DİAZ, p. 569). Es notable la cita que hace Oropesa de Marción, el reformador del siglo II, que siglos después fue del agrado de ciertos Protestantes. Según Bernardino Llorca, Marción "Consecuente con su ideología [i.e. basada en la oposición irreductible entre el Dios del Antiguo Testamento y el Cristo del Nuevo], rechazaba todo el Antiguo Testamento y todo lo del Nuevo intimamente relacionado con aquél. Por esto, fuera de San Pablo, no admitía las enseñanzas de los otros apóstoles, por suponerlos partidarios del Antiguo Testamento" (Historia de la Iglesia Católica, Madrid, Biblioteca de Autores Cristianos, 1955, 2a. ed. t. 1, pp. 220-222). Es algo extraño encontrar que Díaz y Díaz en vez de traducir la referencia que hace Oropesa a Marción; traduce "como escriben los sagrados cánones". También me parece erróneo traducir "evangelium non est in verbis tantum, sed in sentenciis" como "el evangelio no está totalmente en las palabras, smo también en las sentencias". La traducción "el evangelio no está tamo en las palabras, sino en las sentencias" me parece más exacta y corresponde mejor a su cita de Marción: "Nec putemus inquit in ver- 
Dejando atrás lo absurdo del caso, Oropesa se dirigió con la mayor severidad contra los que por envidia o por arrogantes contenciones desgarraban jirones de la Escritura con perjuicio al espíritu evangélico de sus textos. Es de estos falsos celadores de la religión cristiana, declaró fray Alonso, que nacen falsos profetas y herejes que se sirven de las palabras arrancadas de la Biblia para autorizar sus falsas opiniones y satisfacer a sus propias ambiciones de bienes temporales ${ }^{12}$. De semejantes individuos, concluyó Oropesa, surgen ahora los cismáticos que destrozan la unidad de la Iglesia con sus equivocadas distinciones entre cristianos viejos y nuevos ${ }^{13}$.

Evidentemente convencido de la gran importancia de aclarar este asunto, fray Alonso se detuvo a asentar para esos turbadores de la unidad cristiana tres reglas que debieran guiarlos al buen entendimiento de la Biblia. La primera y la más cierta, dijo, es leerla a la luz de la caridad, pues, como escribió San Agustín en su De moribus ecclesiae, "nada queda oculto que no se revele si se busca con caridad. Pues con el amor se pide, con el amor se busca, con el amor se toca, con el amor se revela y, en fin, con el amor permanece lo que se haya revelado"'14. Así, añade Oropesa, el entendimiento verdadero de la Escritura se logra con un celo fuerte de la verdad y procediendo con la tranquila caridad en la disposición deĺ ánimo y el signo de la bondad interior en las buenas obras $^{15}$. La segunda regla es adherirse a la fe según queda expresada en los lugares bíblicos que más clara y firmemente revelan su sentido ${ }^{16}$, y la tercera es aceptar la autoridad de la Igle-

bis Scripturarum esse evangelium sed in sensu, etc.", y también conviene mejor al ejemplo que ofrece Oropesa de los frailes que andan con sus cruces, porque se han fijado en las palabras y no en su sentido.

${ }^{12}$ Oropesa desarrolla bastante ampliamente su denuncia de los que abusan de los textos bíblicos (véase G., fols. 135r-138r; A., fols. 325r-333r; Díaz, pp. 570-581)

18 "Ex hiis etiam prodierunt temporibus nostris hii contra quos ago qui illud antiquissimum scisma quod fuerat ab aposcolo ipso totiens in suis epistolis detestatum, dextructum et reprobatum, nunc ultimo renovantes et ecclesiam Christi in duos populos quos iam Christus ipse in unum coniunxerat dividere innintentes, ipsi ecclesie Dei quantum in eis fuit vulnus lamentabile infixerunt" (G., fol. 136v; A., fol. 329r; DİAZ, pp. 575-576).

${ }^{14}$ G., fols. 138v-139r; A., fols. 333v-334v; DíAZ, pp. 583-584.

${ }^{15} \mathrm{G}$., fol. $139 \mathrm{v}$; A., fol. $336 \mathrm{r}$; DíAZ, pp. 586-587.

${ }^{16}$ G., fol. 139v; A., fol. 336v; DíaZ, p. 587. Oropesa cita el ejemplo de San Pedro que, al predicar la revelación que recibió de las palabras de los profetas "procedere voluit ex firmioribus et planioribus locis scripturarum quantum ad aliquos illorum quibus scribebat et predicabat, nobis in hoc volens relinquere exemplum, ut in doctrina et predicacione nos similiter proce- 
sia, tan estrechamente vinculada a la Escritura que igualmente se puede decir con San Agustín, "no creería en el Evangelio si no me compeliera a ello la autoridad de la Iglesia" y con Juan de Gerson "no creería en la Iglesia si no me compelieran a ello la autoridad del Evangelio y la Sagrada Escritura"1" .

Aquí, habiendo tocado la cuestión de la autoridad de la Iglesia, otra vez vemos a Oropesa característicamente dispuesto a enfrentar el nuevo problema que le ha salido en el camino. Sin intentar seguirle en los detalles de los dos bien nutridos capítulos que dedica a este asunto ${ }^{18}$, baste señalar la conclusión a que llega, a su vez no muy alejada del espíritu de los futuros erasmistas. Para Oropesa, la autoridad de la Iglesia no parece haberse fijado rígidamente en un pasado remoto. Más bien, apoyándose en Ockham y San Agustín, el jerónimo entiende que en el nombre de la Iglesia se incluye toda la congregación de los católicos, de los vivos y los muertos, desde los tiempos de los profetas (sic) y los apóstoles hasta el presente. La Iglesia también consiste en el mismo Santo Evangelio y la Sagrada Escritura y en todas las explicaciones católicas de sus textos ${ }^{19}$. Vista de esta manera, la autoridad eclesiástica se encontraría para Oropesa en un continuo proceso de formulación, siempre abierta a las aportaciones de los nuevos miembros que entran en la congregación de los fieles. Tal concepto de la Iglesia y la autoridad que ejerce había de resonar más tarde entre los que seguían a Erasmo, especialmente al enfrentarse con el problema de si la crítica filológica debía detenerse, según la expresión de Bataillon, "ante la Vulgata como ante un campo prohibido" 20 .

Respecto al tema central de su obra, Oropesa nos indica el camino que va a seguir cuando se detiene a explicar el título que le ha puesto: Lumen ad revelationem gentium et gloria Dei Isra$e l$. Consciente de que sus detractores querrán tomarlo por una proclamación audaz de la grandeza de su libro, fray Alonso re-

damus sumentes ex locis firmioribus et planioribus scripturarum regulam fide et morum si errare non volumus" (G., fol. 140r; A., 337v-338r; DíAZ, p. 589).

${ }^{17}$ G., 141r; A., 340r; DiAz, pp. 592-393.

${ }^{18}$ Los capítulos 46 y 47 del Lumen; en G., fols. 134v-143v; en A., fols. 323v-346r; DíAZ, pp. 568-602.

${ }^{19}$ G., fol. 141r; A., fols. 340v; DíAZ, pp. 593-594.

${ }^{20}$ Bataillon describe cómo Juan de Vergara, en su defensa ante el Santo Oficio, se permite observar que "si fuera herejía confrontar la Vulgata con los originales de los libros bíblicos, habría que proclamar herejes a San Agustín y a San Jerónimo" y también al Cardenal Caietano, a Nicolâs de Lira, al Cardenal Cisneros y aun al Papa León X (op. cit., t. 2, p. 41). 
cuerda en la dedicatoria al Arzobispo Carrillo que con aquellas palabras el justo Simeón recibió al Niño Jesús en la Sinagoga ${ }^{21}$. La "Luz" del título, entonces, se refiere a Jesucristo, gloria del pueblo de Israel en que encarnó para traer a las gentes la perfección de la fe. En efecto, Oropesa levanta la estructura de su $\mathrm{Lu}$ men sobre la idea de la perfección de la fe cristiana en que, como dijo San Pedro, había que fijarse como a una lámpara que brilla en un lugar tenebroso (II, S. Pedro, I, 19). Otra vez tocamos una diferencia fundamental entre el libro de fray Alonso y el Defensorium de Cartagena. Mientras éste organizó su defensa de los conversos a base de la idea de la unidad cristiana, Oropesa se dirigió a la idea más amplia de la perfección de la fe, abarcando así la cuestión de la unidad de los cristianos sólo como una entre varias otras que había que examinar para reclamar los derechos de los fieles de origen judaico.

Así, por ejemplo, desde sus distintos enfoques, ambos apologistas de los conversos se expresaron sobre el desarrollo histórico en que se había realizado la unidad religiosa (en el caso de Cartagena) y la perfección de la religión (desde el punto de vista de Oropesa) en la fe de Jesucristo. Respecto a la unidad cristiana, Cartagena se contentó con señalar el designio misterioso de Dios que se había desarrollado desde la dispersión de los hombres en una multiplicidad de pueblos y creencias que ocurrió después de la creación del único Adán hasta su reunión final con el advenimiento de Cristo. Puesto que no se podía saber por qué Dios obró de esta manera, Cartagena se limitó a describir la dispersión y a señalar los repetidos avisos que los hombres habían recibido de su reunión última en la fe de Jesucristo ${ }^{22}$. Oropesa, por su parte, fijándose principalmente en la perfección religiosa que se había realizado históricamente, encontró la necesidad de explicar en qué consistía esa perfección y de enseñar cómo se había ido alcanzando err las tres etapas de su desarrollo - i.e. cuando los hombres vivían bajo la ley de la naturaleza, luego bajo la ley escrita del Antiguo Testamento y, por fin, cuando les fue revelada la ley de gracia de Cristo. Fue esta manera de concebir la ta-

${ }^{21}$ G., 5v; A., 18v; DiAz, p. 76. En Lucas II, 32 se lee “...et gloriam plebis tuae Israel". Sigüenza da asî el título completo del Lumen $(\mathrm{I}, 370 \mathrm{~b})$ pero los mss. G. y A. sustituyen "Dei", por "tuae". El historiador jerónimo informa que se celebró la recepción de la bula que autorizó el establecimiento de la Orden de San Jerónimo en 1374 "cantando con el santo viejo Simeon. Lumen ad reuelationem gentium, $\mathbb{E}$ gloriam plebis tuae Israel, que creo fue la primera cosa que la religión de S. Geronimo cantó en España" (I, 36b).

${ }^{22}$ Defensorium, ed. cit., pp. 65-92. 
rea de defender a los conversos lo que le llevó a proponer ideas que anticiparon las de Erasmo y sus seguidores en España.

En primer lugar, fray Alonso insistió con un acento particular en que la religión había sido siempre una y la misma, y que a través de las tres etapas de su desarrollo había revelado una perfección que ya había estado implícita desde el principio. Esta idea de la identidad de la religión, permitió a Oropesa declarar que los hombres siempre habían podido salvarse, así bajo la ley natural y la escrita como en la ley de gracia. Esto dicho, fue necesario asentar lo mínimo con que tuvieron que cumplir bajo cualquier ley para ganar la salvación. Con la autoridad de San Pablo (Hebreos, XI, 6), a la cual juntó la de Santo Tomás (Suma Teológica, 2a, 2e, q. 1, ar. 7), Oropesa afirmó que, desde el principio, aun los que vivían según la ley de la naturaleza pudieron salvarse creyendo dos cosas: que Dios existe y que es providente para la salvación del hombre ${ }^{23}$. En estas dos creencias, dijo el jerónimo, se implica en substancia toda nuestra fe en un Dios eterno que es uno y trino y que es nuestra bienaventuranza. También implica el misterio de Su encarnación para salvar a los hombres y todo lo demás ordenado para nuestra salud. Están implícitas estas cosas en las sobredichas creencias, observó Oropesa, de la misma manera que están contenidas en ciertos principios científicos todas las conclusiones que se deducen explícitamente más tarde con grandes trabajos.

Además de parecerse a ios futuros erasmistas por proponer, a su modo, que "creer bien" es lo esencial para la salvación, también sería pre-erasmista lo que escribió Oropesa sobre los sacrificios. El culto de los sacrificios según él, como la fe misma, también había sido siempre sustancialmente idéntico. Pues, a pesar de la gran variedad de ofrendas que se traían a Dios en distintos lugares y la variable frecuencia de celebrarse los sacrificios, éstos nunca fueron otra cosa que una especie de "protestación" de la fe interior que se hacía presentando alguna oblación exterior a Dios en reverencia, culto y honor para declarar que es el Creador del hombre y el fin último de nuestra bienaventuranza ${ }^{24}$. Vinculados de esta manera fe y sacrificios, Oropesa pudo aceptar lo que Santo Tomás había escrito en varias ocasiones respecto a nunca haber bastado la fe sola para justificación, ni aun cuando los hombres vivían bajo la ley de la naturaleza. Porque el sacrificio, visto como una necesidad de expresar la credulidad interior del hombre, na-

${ }^{23}$ G., fol. $16 r$; A., fols, 43 v- 44 r; DíAZ, p. 124 .

${ }^{24}$ G., fols. 14v-15r; A., fols. 40v-42r; DíAZ, pp. 119-121. 
ce al nacer la fe, dijo Oropesa, y crece con ella y con ella durará in finem. Por eso añadió, hay que suponer, como lo demostró Santo Tomás, que también Adán e Isaac hacían sacrificios, a pesar de no hacerse mención de ello en la Biblia ${ }^{25}$.

El sentido en que Oropesa entiende ser inseparables fe y sacrificios resuena en varios otros asuntos que toca y que, en el siglo XVI, habían de ser de primera importancia para Erasmo y sus partidarios españoles. Así, por ejemplo, fray Alonso se acerca a la cuestión de si las obras sin fe justifican en su antes mencionada cita de Hebreos, XI. De este capítulo de la epístola paulina, donde el Apóstol recuerda a los que agradaron a Dios con sus obras - entre ellos, Abel, Enoc, Noé y Abrahán - Oropesa se refiere al versículo seis que declara que "sin fe es imposible agradar a Dios" ${ }^{26}$, lo cual subraya que los sacrificios de aquellos precristianos sólo fueron gratos a Dios por la fe con que se hicieron. Más adelante, encontramos a fray Alonso dirigiéndose contra los judeocristianos de la Iglesia Primitiva por oponerse a la recepción como iguales de los convertidos del paganismo, denunciando a los primeros por su "ceguera" y por "judaizar" contra los cristianos gentílicos ${ }^{27}$. Y entonces, apoyándose otra vez en San Pablo, ahora en Romanos III, 28-30, recuerda su declaración, a propósito de los que se enorgullecían por sus obras, de que la justificación del hombre era por la fe, sin las obras de la ley ${ }^{28}$.

No muy alejada de lo sobredicho es la introducción que hace Oropesa del tema de la gracia de Dios. Mientras está describiendo el amor y la paz en que Cristo reunió a judíos y gentiles, se detiene para destacar la gracia insólita que Cristo les concedió a todos los fieles de invocar a Dios como Padre en la oración del "Padre nuestro". Luego amplía la idea de lo que se debe a la gracia divina cuando pasa a declarar que es puramente por ella que todos los fieles alcanzan reconocerse como hermanos en Cristo, citando sobre esto a San Agustín: "Somos llamados a la herencia eterna para que seamos coherederos con Cristo y alcancemos la adopción como hijos de Dios, no por nuestros méritos sino por la gracia de Dios"'?2.

Respecto a los temas ya mencionados que Oropesa toca al desarrollar su argumentación en favor de los conversos sinceros, es

${ }^{25}$ G., fol. 15r; A., fol. 42r; DÍAZ, pp. 121.

${ }^{26}$ G., fol. 12r; A., fol. 35r; DíAz, p. 108.

${ }^{27}$ G., fol. 71v; A., 176r; DíAZ, p. 339.

${ }^{28}$ G. , fol. 73r; A., fol. 179r; DíAZ, p. 344. Véase también G., fol. 76v; A., fol. 188r; DÍAZ, pp. 358-359.

${ }^{29}$ G., fol. $10 \mathrm{lr}$; A., fol. 242v; DİAZ, p. 447. 
notable que no los trata con la profundidad de los espirituales del siglo XVI. Quizás sea así porque le interesan más bien por lo que contribuyen a su propósito apologético inmediato que como cuestiones puramente teológicas. De manera semejante se puede explicar su mayor detenimiento en la virtud de la caridad que para él es la perfección cristiana por excelencia. Pues aquí sí, tratándose de un tema cristiano más directa y profundamente relacionado con el problema de la recepción de los nuevos convertidos del judaísmo, parece dispuesto a agotarlo en la medida que le permita hacerlo toda su preparación religiosa.

Otra vez, viene al caso comparar a Oropesa con Cartagena, para ver cómo teniendo en común el mismo propósito fundamental y aun sirviéndose a veces de las mismas materias, sin embargo se lanzan por distintos caminos para llevar a cabo su tarea. Lo curioso, y para nosotros lo más importante, es que, habiendo recorrido vías distintas, no es a la misma "Roma" que llegan ambos apologistas. Así, los datos que le sirvieron a Cartagena para indicar la imperfecta unidad de los fieles antes de Cristo, para Oropesa fueron indicativos de la imperfecta caridad en que vivían antes de la ley de gracia. El jerónimo, en efecto, repitió lo que el obispo de Burgos escribió en su Defensorium del exclusivismo de los judíos bajo la ley del Antiguo Testamento, de su considerar "advenedizos" a ios gentiles que se acercaron a la $\mathrm{Si}$ nagoga y de la exclusión de los oficios del templo no sólo de ellos sino también de los judíos que no eran de la tribu de Levíi ${ }^{30}$. También se repitió en el Lumen lo que Cartagena señaló respecto a haber juntado Cristo a judíos y gentiles en los momentos más importantes de su vida, desde su Nacimiento hasta su Pasión, creando así un nuevo pueblo sin distinciones entre ellos y devolviendo el sacerdocio a todos los fieles capacitados para ejercer$10^{31}$. Pero para fray Alonso todos estos datos indicaron la imperfección de la caridad antes de Cristo y el perfeccionamiento más importante de su religión.

Con todas las excursiones a la variedad de temas que se permite Alonso de Oropesa en el Lumen, queda, sin embargo, clarísimamente destacado el argumento central de su obra: anulando antiguos odios, enemistades y rivalidades, el pueblo cristiano ha de convivir en paz y concordia, vinculándose todos los fieles en los lazos de amor y caridad. Tanta es la insistencia de

${ }^{30}$ G., fols. 87v-88r; A., fols. 213r-v; DİAZ, p. 401.

${ }^{31}$ G., fol. 89v; A., fols. 217r-v; DíAZ, pp. 406-407. Véase también el $D e$ fensorium, ed. cit., pp, 142-143. 
fray Alonso en este aspecto de la perfección cristiana, que su libro parece verdaderamente una anticipación de la Querela pacis de Erasmo, obra que, a mi ver, no por nada fue una de las primeras del holandés traducidas al español. Otra vez, fue Marcel Bataillon quien nos abrió la posibilidad de establecer el terreno común de que surgió el Lumen en el siglo XV y una traducción española del tratado que Erasmo compuso en 1516 con miras a la situación política que amenazaba entonces a la cristiandad en Europa. "Sin duda, escribió Bataillon, fue el valor humano de la Querela pacis y no su significado momentáneo, lo que sedujo a Cortegana [a traducirla]. Esta hermosa lección de filosofía cristiana merece retener nuestra atención, tanto más cuanto que es uno de los primeros mensajes de Erasmo que llegaron al gran público español"32. Aceptando que la obra de Eras mo no fue traducida "por su significado momentáneo", podemos preguntarnos ahora si, en vez de su "valor humano", lo que le atrajo al ex inquisidor Diego López de Cortegana a la Querela pacis fuera su utilidad para reducir disensiones entre cristianos viejos y nuevos, en su país. En este caso, se podría entender que Cortegana importó la medicina de un prestigioso curandero extranjero de disensiones entre cristianos para sanar las de su propia patria ${ }^{33}$.

En el Lumen de Oropesa, el amor y la caridad quedan instalados al centro de su visión cristiana desde las primeras palabras del prefacio que dirige el Arzobispo Carrillo. Se sirve de una cita de San Juan Crisóstomo (de su $2^{\mathrm{a}}$ homilía sobre I Timoteo) para declarar que nada es tan perjudicial al género humano como el menosprecio de la amistad y el descuido de las buenas relaciones entre los hombres. De ahí nacen las herejías, pues al no amarse los hermanos, se envidian, y de la envidia pasan al deseo de dominar y por fin de esta ambición surgen las herejías. Por otro lado, se entiende de las palabras de Jesucristo que donde dos hombres se pongan de acuerdo conseguirán todo lo que pidan ${ }^{34}$. Este aprecio de la caridad cristiana será el punto de partida para

${ }^{32}$ Bataillon, op. cit., t. 1, p. 101

${ }^{33}$ Respecto al traductor de la Querela pacis, quizás sea significativo que habiendo sido nombrado sucesor al puesto inquisitorial de Lucero en 1508 , Diego López de Cortegana fue destituido, según informa Bataillon, porque "había querido revocar una de sus sentencias [i.e. de Lucero] y devolver a una de sus víctimas ciertos bienes injustamente confiscados" (op. cit., t. 1, p. 100). Evidentemente el espíritu cristiano de Cortegana no era el de los vigilantes inquisitoriales del cristianismo.

${ }^{34}$ G., fol. 1r; A., fols. 7r-v; DíAz, p. 60. 
llegar, en el capítulo 49 donde termina la exposición doctrinal del Lumen, a destacar el sentido de la visión de San Juan en Apocalipsis I, 13. Allí se le reveló Jesús ceñidos los pechos con un cinturón de oro, por lo cual se entiende la reunión en Cristo de los fieles de ambos pueblos, de los judíos y los gentiles, recogidos en el lazo de oro que es la caridad. Pues así como el oro excede en preciosidad y valor a todos los metales, dice Oropesa, así la caridad supera a las otras virtudes. Esto está de acuerdo, concluye, con I Corintios, XIII, evidentemente refiriéndose al versículo 13 en que San Pablo anuncia: "Pues ahora subsisten fe, esperanza, caridad; estas tres, aunque la mayor de ellas es la caridad"

A esta idea de la perfecta caridad en que deben convivir todos los cristianos está asociada, según fray Alonso, otra perfección del cristianismo, la que alcanza en el culto del sacrificio. Importa notar aquí que en el Defensorium Cartagena condenó la discriminación racial contra los judeocristianos porque desdecía de la eficacia del sacramento del bautismo, negando en efecto que pudiera lavar los pecados de todos - sin excepción de los judíos - los que se convirtieron al cristianismo ${ }^{36}$. Para Oropesa, en cambio, la exclusión de los conversos de la compañía de los fieles parece haber sido principalmente un agravio al sacramento de la comunión. Porque precisamente a esto, escribió fray Alonso, había llegado la gran diversidad de sacrificios y ofrendas de antes, es decir, al sacrificio altísimo y perfectísimo del Hijo de Dios que ofrece la vida eterna a los que participan de su carne y de su sangre ${ }^{37}$. El sacrificio cristiano, entonces, es al pie de la letra comunión de la cual no se puede excluir a los de origen judaico. $\mathrm{Y}$ aquí se apoya el jerónimo en la metáfora paulina según la expresa el Apóstol en I Corintios X, 15-17: "Puesto que uno es el panl, un cuerpo somos la muchedumbre; pues todos de un solo pan participamos" a lo cual añade lo que explica la Glosa: "Todos los que participamos de un pan, es decir del Cuerpo de Cristo, y de un cáliz, es decir de su sangre, aunque somos muchos, sin embargo somos un pan en la unión de la fe, de la esperanza y de la caridad, y un cuerpo de aquella Cabeza que es Cristo..." ${ }^{38}$ Oropesa sigue la cita de la Glosa hasta introducir la nota de particular interés para nosotros: “...figurativamente, pues, la Iglesia dice ser un pan y un cuerpo por-

${ }^{85}$ G., fol. 159r; A., fols. 379v-380r; DíAz, p. 656. En la Vulgata, I Ad Corinthios XII, 13 dice: "Nunc autem manent, fides, spes, charitas: tria haec; maior autem horum est charitas".

${ }^{36}$ Defensorium, ed. cit., pp. 182-183.

${ }^{37}$ G., fols. 77v-78r; A., fols. 190r-191v; DiAZ, pp. 361-366.

${ }^{38}$ G., fol .78v; A., fol. 192v; DíAZ, p. 367. 
que así como un pan se compone de muchos granos y un cuerpo de muchos miembros, así la Iglesia de Cristo está vinculada de muchos fieles aunados en la caridad"39.

Llegamos, entonces, a una de las muchas ocasiones que se podrían citar en que se confirma la conjetura de Marcel Bataillon en cuanto a que en España se manejó la figura paulina del Cuerpo Místico antes de identificarse con la doctrina de Erasmo. Sin embargo, tenemos que notar que se confirma la idea de Bataillon sólo en parte, en un sentido significativamente limitado. Resulta que el uso que Oropesa hizo de la metáfora de San Pablo - y antes que él, Cartagena - como un argumento para admitir a los judeoconversos al cuerpo cristiano no alcanzó la altura espiritual que concibió Erasmo al emplear la misma figura. Nada se encuentra ni en el Lumen ni en el Defensorium que sugiera el concepto erasmista de un Cuerpo Místico en que fluye la sangre del Crucificado, desde la Cabeza que es Jesucristo hasta el hombre que es el miembro más ínfimo del Cuerpo ${ }^{40}$. Parece, entonces, que a los apologistas de los conversos les interesaba la figura en un sentido más cercano a la idea del Apóstol, la de señalar a la vez la unidad del Cuerpo y la diversidad de los miembros que desempeñaban funciones diferentes. De esta manera, la metáfora de San Pablo serviría el propósito de reconciliar a judeocristianos y cristianos gentílicos en un cuerpo eclesiástico con sus funciones diversas, dejando en un segundo término la preocupación erasmista de la relación de cada cristiano con Dios ${ }^{41}$.

Sin embargo, aunque ni Cartagena ni Oropesa alcanzaron el sentido más altamente espiritual que la figura paulina había de tener para Erasmo, hubo una nota de diferencia entre el obispo y el fraile que otra vez permite ver cómo éste se acercó más al espíritu de las doctrinas del holandés. A Cartagena le importó insistir en la diversidad de los miembros del cuerpo cristiano principalmente porque servía su interés en conservar los privilegios y preeminencias debidos a los judíos de estado más elevado que se convirtieron a la religión cristiana. Evitando toda mención de que él mismo era hijo de un ex rabino que más tarde ocupó la sede principal de Burgos, Cartagena prefirió señalar a los gentiles que

${ }^{39} \mathrm{G}$., fol. 79r; A., fol. 193r; DíAZ, p. 367.

${ }^{40}$ Bataillon, op. cit., $2^{\mathrm{a}}$. ed., México, 1966, p. 208.

${ }^{41}$ Según P. Emilio Sauras, O. P., el adjetivo "místico" aplicado a la figura del cuerpo de la Iglesia no será auténticamente de acuerdo con la idea del Apóstol sino más bien pertenece a una tradición teológica posterior a San Pablo. Véase su libro sobre El cuerpo mistico de Cristo, segunda edición, Madrid (Biblioteca de Autores Cristianos), 1956, pp. 62-3 y 122 ss. 
por ser o descender de emperadores, reyes y príncipes fueron recibidos con mayor respeto en la Iglesia. La conservación de sus distinciones nunca se vio como contraria a la fe de Jesucristo y, por consiguiente, podía aplicarse a los judíos que por sus orígenes más distinguidos merecían mayor miramiento al entrar en la Iglesia. Mantener tales distinciones entre los que se reciben en la fe, declaró Cartagena, no quita nada de la unidad del cuerpo cristiano que, así como el cuerpo humano, tiene diversos miembros con diversas funciones. El hecho de ejercer uno el oficio de "ojo" y otro el de "pie", según el obispo, no perjudica la integridad del cuerpo, sea el humano o sea el de la figura paulina ${ }^{42}$.

Mientras Cartagena procuró demostrar la legitimidad de conservar las preeminencias antiguas de los nuevamente convertidos, para Oropesa lo más importante era mantener abierto el acceso a los dones y beneficios de la Iglesia a todos los fieles idóneos para ejercerlos, fuesen de descendientes de judíos o de gentiles, quienes debían sus habilidades a la gracia de Dios. Según fray Alonso "por la lluvia de la gracia del Espíritu Santo que sobre todos ellos entonces [i.e. en la Iglesia Primitiva] descendió visiblemente y después sobre los fieles de la Iglesia invisiblemente se indica y se muestra descender de esta gracia del Espíritu Santo todos los otros dones, oficios y beneficios de la Iglesia militante, como de una fuente y principal manantial. Y se dan a los fieles de la Iglesia para la utilidad común y la edificación del Cuerpo Místico de Cristo que es la Iglesia. Según escribe más largamente el Apóstol en I Corintios XII y en Efesios IV, deben ser comunes a todos y a cada uno de los fieles de ambos pueblos, de acuerdo con la capacidad y mérito y suficiencia de cada uno de ellos, según la distribución recta y justa, sin acepción de personas, del vicario de Cristo" 43 . Con esta cita típica de lo que Oropesa tiene que decir del cuerpo más bien "único" que al pie de la letra "místico" de la Iglesia, vemos claramente el trecho que le quedó todavía para dar plenamente con la espiritualidad erasmista.

Encontramos lo mismo, con aún mayor claridad, cuando Oropesa comenta la súplica de Cristo a su Padre: "Que sean todos unos como tú, Padre, eres en mí y yo en ti, que ellos también sean uno en nosotros" (San Juan, XVII, 21) ) $^{44}$. Si más tarde estas palabras habían de significar para Erasmo, como lo notó Bataillon, que Jesucristo pidió que fuesen todos uno con Él y su Padre, y no

${ }^{42}$ Defensorium, ed. cit., pp. 150, 157, 248.

${ }^{43}$ G., fol. 170v; A., fol. 406v; DíAz, p. 696.

${ }^{44}$ G., fol. 154r; A., fol. 368r; DíAz, pp. 638-639. 
sencillamente "unánimes" pues "se trata de la más perfecta, de la más inefable unidad" "45, no tenían el mismo sentido para Oropesa. Pues éste, después de citar la súplica de Cristo, escribió: "No es, sin embargo, esta unidad de todos ios fieles como es la unidad del Padre con el Hijo, sino que la unidad es como cierta imitación porque de Cristo hombre y Dios la unidad es personal. La unidad, verdaderamente, del Hijo de Dios y del Padre es una unidad de esencia. La unidad de los otros hombres fieles con Dios es de la caridad y de la paz, de la buena voluntad, y de ellos en todos los bienes de la Iglesia y de su íntima fraternidad en que consiste la perfección de toda la religión cristiana" ${ }^{46}$.

Topamos aquí con el punto límite del pre-erasmismo de Oropesa, cuyo significado hace falta, por lo menos, intentar discernir para entender cómo en el terreno preparado por el jerónimo pudo arraigar y florecer la espiritualidad de los erasmistas en España y la de otros espirituales que, según la expresión de Bataillon, desplegaron "actitudes afines a la de Erasmo" 47 . Para entender la indisposición de fray Alonso de tomar al pie de la letra, como más tarde lo hizo Erasmo, el ruego de Cristo de ser los fieles "uno" con Dios y su Hijo, quizás se debiera arriesgar la conjetura de un residuo atávico de judaísmo en un Oropesa que en efecto fue converso. En este caso, se hubiera sentido tan incómodo como sus antepasados judíos con la idea de una fusión esencial del hombre con su Dios en un cuerpo de la Iglesia que sería verdaderamente místico. Sin rechazar categóricamente esta explicación, se podría ofrecer otra más evidente, fundada en la razón de ser histórica de la obra de fray Alonso. No cabe duda de que el Lumen, así como todas las demás apologías del converso del siglo $\mathrm{XV}$, fue compuesto cuando todavía se esperaba poder reclamar eficazmente la aceptación de los convertidos del judaísmo en plan de igualdad con todos los fieles sinceros del cuerpo cristiano. Las anticipaciones de procedimientos y temas erasmistas que encontramos en el Lumen no tenían otro fin inmediato que el de permitir la asimilación de los conversos, a la vez social y religiosa, en el mundo cristiano español. Por eso, Oropesa pudo tocar, según hemos visto, una gran variedad de asuntos que tenían implicaciones profundas para la regeneración de la espiritualidad cristiana sin seguir él sus últimas conse.

${ }^{45}$ Bataillon, op. cit., t. 1. p. 102.

${ }^{46} \mathrm{G}$., fol. 154r; A., fols. 368r-v; DíAZ, p. 639.

${ }^{47}$ Ibid., t. 1, p. XV del Prólogo donde el autor explica el criterio amplio que le guió en su estudio del "erasmismo" en España. 
cuencias. Estas, en fin de cuentas, tendrían que ver con la vida espiritual de cada individuo cristiano, de su manera de vivir su relación con Dios. Ocupado en primer término con el problema colectivo de los conversos, Oropesa no estaba en condiciones de empujar tan lejos sus consideraciones sobre la perfección de la religión de Cristo. Ahora bien, pudiéramos sugerir, como conclusión de este ensayo, que los conversos que eran cristianos sinceros, aquéllos para quienes ya no era cuestión volver al judaísmo de sus antepasados, häbían de lanzarse a nuevas aventuras espirituales en su cristianismo a medida que iba empeorando su situación colectiva. La cronología de su destino en España justifica sobradamente nuestra tesis ${ }^{48}$. En las primeras décadas del siglo XVI no cabía la menor duda de que habían fracasado rotundamente los propósitos de Alonso de Cartagena y Alonso de Oropesa y de varios apologistas menores de liberar a los conver-

${ }^{48}$ Terminado este trabajo, se me ocurre que debo advertir al que lo lea que poco o nada de lo que he escrito aquí se semeja a lo que el traductor de la obra de Oropesa parece haber entendido de ella. A juzgar por la introducción que Luis Díaz pone a Luz para conocimiento de los gentiles, o no ha entendido o concede poca importancia al nuevo espíritu religioso que brotó en esta obra escrita a mediados del siglo XV por un fraile jerónimo. Lo que es más grave, en una sección sobre la "tesis teológica de la obra" (pp. 35 ss.) introduce confusiones que desviarían la atención del lector del verdadero significado de la obra de Oropesa. Así, por ejemplo, después de notar que los que han escrito sobre el Lumen "coinciden en que es una defensa de los conversos del judaísmo", propone la idea de que "el intento del autor y el contenido de la obra apuntan más hondo". Por un momento se puede estar de acuerdo con el traductor, cuando declara que "la intención de fray Alonso es equivalente a la de San Pablo al afirmar la igualdad en el Evangelio de griegos y judíos, aunque ahora vista del lado opuesto". Pero se comienza a dudar de su entendimiento del Lumen cuando desemboca en la idea de que "la intención más profunda de la obra de fray Alonso consiste realmente en defender los derechos de Cristo" (p. 36); y añade en la próxima página:"En ese sentido la obra de fray Alonso no es tanto defender los derechos de los conversos a la fe de Cristo procedentes del judaísmo (tesis que podemos considerar como tesis histórica), cuando el defender los derechos del mismo Cristo y de su obra redentora, así como su aplicación sacramental a los creyentes (tesis que habrá que considerar como tesis teológica): con otras palabras, la igualdad de los creyentes dentro de la perfecta unidad que Cristo concedió definitivamente a su Iglesia". Me parece que la confusión se aclara con lo que Díaz y Díaz escribió en otro estudio suyo sobre Oropesa y su Lumen respecto a no poder "separarse adecuadamente los dos intentos que el libro incluye, exponer la doctrina sobre la obra de Cristo realizando una Iglesia única y perfecta, y hacer callar a los detractores de los judíos conversos al cristianismo, quitando el oprobio de que eran objeto y elevándolos a la igualdad con todos los creyentes" (véase su artículo "Alonso de Oropesa y su obra" en Studia Hieronymiana, Madrid, 1973, t. 1, p. 280). El hecho de que el traductor no repita esta observación en 
sos de las discriminaciones categóricas de que eran víctimas. Perdida su situación colectiva - tener sangre limpia estaba en camino de establecerse como un requisito dogmático para una existencia normal en España - conversos individuales se hacen desproporcionadamente numerosos en los movimientos espirituales de vanguardia del siglo XVI, de los alumbrados y místicos así como de los erasmistas, todos en busca de una redención religiosa personal, ya que les quedó cerrado el camino a la aceptación colectiva en la sociedad española.

A. A. SICROFF

Queens College of the City University of New York.

la introducción al $L u z$ indica el problema con que nos deja. Parece relegar a un segundo término la cuestión conversa, que es la razón de ser de la obra, para acentuar el problema cristológico que Oropesa trata en el Lumen. Pero la lectura del libro nos demuestra que Díaz y Díaz ha trastocado completamente la preocupación inmediata con que escribe Oropesa en cada momento y las consecuencias de mayor alcance (algunas de las cuales hemos tratado de describir en el presente estudio) a que se llega en esta apología en favor de los conversos. Como he tratado de demostrar en los últimos párrafos, Oropesa no llega a anticipar el paulinismo de los conversos como un teólogo preocupado por cuestiones cristológicas, sino como defensor de los conversos. Con este propósito comenzó el libro en 1450 y con el mismo propósito volvió a acabarlo en 1465. Importa guardar esto en la memoria para no confundir la consecuencia con la causa, habiendo sido ésta el problema perenne de los conversos en España - lo cual ocasionó una obra como el Lumen, entre muchas otras cosas que no me ha tocado abarcar en este ensayo. 